\title{
Sexual Dimorphism in Blood Pressure and Hypertension among Adult Parengi Porjas of Visakhapatnam, Andhra Pradesh, India
}

\author{
I. Arjun Rao, ${ }^{1}$ Adimoolam Chandrasekhar, ${ }^{2}$ Venugopal N. Pulamaghatta, ${ }^{3}$ \\ Subal Das, ${ }^{4}$ and Kaushik Bose ${ }^{5}$ \\ ${ }^{1}$ Department of Forensic Sciences, GGV, Bilaspur, India \\ ${ }^{2}$ Anthropological Survey of India, Southern Regional Centre, Mysore, India \\ ${ }^{3}$ Anthropological Survey of India, North-West Regional Center, Dehradun, India \\ ${ }^{4}$ Department of Anthropology and Tribal Development, Guru Ghasidas Vishwavidyalaya, Koni, \\ Bilaspur, Chhatisgarh 495009, India \\ ${ }^{5}$ Department of Anthropology, Vidyasagar University, West Bengal, India
}

Correspondence should be addressed to Subal Das; das_vu@rediffmail.com

Received 25 November 2013; Revised 13 March 2014; Accepted 24 March 2014; Published 10 April 2014

Academic Editor: Santos Alonso

Copyright (C) 2014 I. Arjun Rao et al. This is an open access article distributed under the Creative Commons Attribution License, which permits unrestricted use, distribution, and reproduction in any medium, provided the original work is properly cited.

\begin{abstract}
The present study investigated blood pressure levels as well as the prevalence of hypertension among adult Parengi Porja tribals of village Munchingput Mandalam, Visakhapatnam district, Andhra Pradesh, India. A cross-sectional study was used to collect data on systolic blood pressure (SBP), diastolic blood pressure (DBP), and pulse rate. A total of 137 adults (100 males and 37 females) were measured and classified into three age groups, that is, Gr-I: 23 to 32 years, Gr-II: 33 to 42 years, and Gr-III: $\geq 43$ years. Negative significant sex difference in SBP among age group I $(t=-2.409 ; P<0.05)$ was observed. Positive significant sex difference in DBP among age group I $(t=2.545 ; P<0.05)$ was also observed. Significant age group difference was noticed for SBP $(F=4.332$; $P<0.01)$ among males. Based on SBP, the prevalence of prehypertension and stage I hypertension in males was $25.0 \%$ and $5.0 \%$, respectively. Similarly, in females the prevalence of prehypertension and stage I hypertension based on SBP was $32.4 \%$ and $5.4 \%$, respectively. On the basis of DBP, the prevalence of stage I hypertension in males was $5.0 \%$. Similarly, in females, the prevalence of stage I hypertension based on DBP was 5.4\%. Our results suggest that females of this ethnic group were more prone to have prehypertension and stage I hypertension than males.
\end{abstract}

\section{Introduction}

Hypertension is a major modifiable risk factor, which significantly and independently increases the risk of developing cardiovascular disease (CV) complications. On the other hand, an effective treatment of hypertension substantially reduces the risk of developing such complications [1]. Although importance of blood pressure as a risk factor in cardiovascular disease is well established [2-4], how blood pressure is influenced by different environmental factors is the key for the understanding of coronary diseases. The people of South Asian origin have increased cardiovascular risk due to more centralized deposition of body fat with higher mean of WC and WHR compared to Europeans [5-7].
Since hypertension is an ideal identifiable target to reduce global cardiovascular risk, it is clear that effective strategies, aimed at improving high BP control in the general population of hypertensive patients, represent a fundamental step of any preventive strategy in our country. Therefore, the purpose of the present study was to screen adults Porjas, a Particularly Vulnerable Tribal Group (PTG) of Visakhapatnam, Andhra Pradesh, India, for blood pressure and hypertension status. Hitherto, information on blood pressure among adult Porja tribals of Visakhapatnam, Andhra Pradesh, India, is limited.

\section{Materials and Methods}

The present cross-sectional study was conducted in Visakhapatnam, Andhra Pradesh, India. Visakhapatnam is situated 
TABLE 1: Descriptive statistics and $t$-test among the subjects.

\begin{tabular}{|c|c|c|c|c|c|}
\hline Variables & Sex & $N$ & Mean & $\mathrm{SD}$ & $t$ \\
\hline \multirow{2}{*}{ SBP } & $\mathrm{M}$ & 100 & 119.1700 & 9.53786 & \multirow{2}{*}{-1.090} \\
\hline & $\mathrm{F}$ & 37 & 121.1351 & 8.88558 & \\
\hline \multirow{2}{*}{ DBP } & $\mathrm{M}$ & 100 & 66.2500 & 10.51826 & \multirow{2}{*}{1.309} \\
\hline & $\mathrm{F}$ & 37 & 63.4865 & 12.12349 & \\
\hline \multirow{2}{*}{ MAP } & $\mathrm{M}$ & 100 & 83.8900 & 8.16910 & \multirow{2}{*}{0.758} \\
\hline & $\mathrm{F}$ & 37 & 82.7027 & 8.05107 & \\
\hline
\end{tabular}

about $75 \mathrm{~km}$ from village Munchingput Mandalam, Visakhapatnam. A total of 137 adults (100 males and 37 females) aged above 23 years were measured for blood pressure. Porja are mainly distributed near the hill slopes of Munchangiputtu, Ananthagiri, and Pedabayalu mandal of Visakhapatnam district of Andhra Pradesh. Their population as per 2001 census is 32,669 among whom males are 16,132 and females are 16,537. The total literacy rate among Porja is 26.55 according to 2001 census. They are recognized as Particularly Vulnerable Tribal Group (PTG). They have their own dialect. In addition to their own dialect, they speak Telugu as well as Adivasi Oriya. They are said to be a section of Khond/Gadaba tribe of Ganjam district [8]. There are 7 endogamous units who differ in language, food habits, customs, and traditions. The Porja living in Andhra Pradesh belong to the Parengi Porja $[9,10]$ on whom the present study has been conducted. Pirangi Porja population can be found in Paderu, Araku (Munchingputtu Mandal) of Visakhapatnam district. They belonging to Austro Asiatic linguistic family where recently migrated from Orissa [11]. Most of the Porja are farmers and day laborers. They live in houses made of wattle thatch (poles intertwined with twigs, reeds, or branches). Porja community is patriarchal (male dominated) and patrilineal (descent through male lineage). The eldest male is the head of the family. Cross cousin marriages are preferred, and marriages are often polygamous (having multiple spouses).

This study was carried out during March-April, 2012. Data were collected after obtaining the necessary approval from the competent authorities. Informed consent was also obtained from each participant. Information on age, gender, and blood pressure measurements was collected on a pretested questionnaire by house-to-house visit following interview and average of three consecutive measurements (following 2 minutes gap between readings) was recorded. The measurements were taken from the participant during day time. Subjects were classified into three age groups, that is, Gr-I: 23 to 32 years, Gr-II: 33 to 42 years, and Gr-III: $\geq 43$ years. And the sex wise distributions among males and females in each age group are 27, 41, and 32 in males and 20, 13, and 4 in females.

The physiometric variables included measurement of systolic blood pressure (SBP), diastolic blood pressure (DBP), and pulse rate. Two consecutive readings were recorded for each of SBP and DBP and the averages were used. The measurements were taken with the help of digital blood pressure machine in a sitting position with the left forearm placed horizontal on the table. All efforts were made to minimize the factors which affect blood pressure like anxiety, fear, stress, laughing, and recent activity [12]. Blood pressure was categorized as normal BP based on SBP/DBP as less than $120 / 80 \mathrm{mmHg}$, prehypertension as $120-139 / 80-89 \mathrm{mmHg}$, stage I hypertension as 140-159/90-99 $\mathrm{mmHg}$, and stage II hypertension as equal to and above $160 / 100 \mathrm{mmHg}$ [13].

Mean arterial blood pressure (MAP) was calculated for each of the two readings taken for SBP and DBP by using the followingstandard formula:

$$
\mathrm{MBP}=\mathrm{DBP}+\frac{(\mathrm{SBP}-\mathrm{DBP})}{3} .
$$

See [14].

All data were analyzed by SPSS (Statistical Package for Social Sciences, Version 16). Mean, standard deviation, independent samples $t$-test, ANOVA ( $F$-test), and Chi-square test $\left(\chi^{2}\right)$ were performed to investigate age and sex variations.

\section{Results}

Table 1 presents the means, standard deviations, and $t$-test between the sexes of the studied variables. There was no significant sex difference in mean SBP, DBP, and MAP.

Mean, standard deviation, $t$-test, and $F$-test (ANOVA) of the studied variables, namely, SBP $(\mathrm{mm} / \mathrm{Hg}), \mathrm{DBP}(\mathrm{mm} / \mathrm{Hg})$, and mean arterial pressure (MAP) $(\mathrm{mm} / \mathrm{Hg})$, of three different age groups of males and females are presented in Table 2. Negative significant sex difference in SBP among age group I $(t=-2.409 ; P<0.05)$ was observed. Positive significant sex difference in DBP among age group I $(t=2.545 ; P<$ $0.05)$ was also observed. Significant age group difference was noticed for SBP $(F=4.332 ; P<0.01)$ among males.

Table 3 shows the correlation matrix of age with SBP, DBP, and MAP for both sexes. It can be observed from the table that there was no significant correlation between age and blood pressure among the subjects.

Table 4 presents the prevalence of hypertension based on SBP and DBP. On the basis of SBP, the prevalence of prehypertension and stage I hypertension in males was $25.0 \%$ and $5.0 \%$, respectively. Similarly, in females, the prevalence of prehypertension and stage I hypertension based on SBP was $32.4 \%$ and $5.4 \%$, respectively. On the basis of DBP, the prevalence of stage I hypertension in males was $5.0 \%$. Similarly, in females the prevalence of stage I hypertension based on DBP was $5.4 \%$. 
TABLE 2: Age-sex specific descriptive statistics of the subjects.

\begin{tabular}{|c|c|c|c|c|c|c|c|c|}
\hline \multirow{2}{*}{ Variables } & \multirow{2}{*}{ Age group (years) } & \multicolumn{3}{|c|}{ Males } & \multicolumn{3}{|c|}{ Females } & \multirow{2}{*}{$t$} \\
\hline & & $N$ & Mean & SD & $N$ & Mean & SD & \\
\hline \multirow{4}{*}{ Age (years) } & $(23-32)$ & 27 & 28.70 & 2.77 & 20 & 29.00 & 2.60 & -0.372 \\
\hline & $(33-42)$ & 41 & 38.24 & 2.91 & 13 & 38.00 & 2.83 & 0.265 \\
\hline & $(\geq 43)$ & 32 & 50.28 & 3.57 & 4 & 47.50 & 2.89 & 1.493 \\
\hline & $F$ & 100 & \multicolumn{2}{|c|}{$360.827^{* * *}$} & 37 & \multicolumn{2}{|c|}{$98.042^{* * *}$} & \\
\hline \multirow{4}{*}{$\mathrm{SBP}(\mathrm{mm} / \mathrm{Hg})$} & $(23-32)$ & 27 & 116.33 & 7.52 & 20 & 121.85 & 8.07 & $-2.409^{*}$ \\
\hline & $(33-42)$ & 41 & 122.39 & 9.74 & 13 & 121.15 & 10.86 & 0.388 \\
\hline & $(\geq 43)$ & 32 & 117.44 & 9.84 & 4 & 117.50 & 6.45 & -0.012 \\
\hline & $F$ & 100 & \multicolumn{2}{|c|}{$4.332^{* *}$} & 37 & \multicolumn{2}{|c|}{0.386} & \\
\hline \multirow{4}{*}{$\mathrm{DBP}(\mathrm{mm} / \mathrm{Hg})$} & $(23-32)$ & 27 & 65.26 & 9.55 & 20 & 64.40 & 14.41 & 0.246 \\
\hline & $(33-42)$ & 41 & 64.78 & 11.81 & 13 & 64.08 & 9.74 & 0.195 \\
\hline & $(\geq 43)$ & 32 & 68.97 & 9.25 & 4 & 57.00 & 2.45 & $2.545^{*}$ \\
\hline & $F$ & 100 & \multicolumn{2}{|c|}{1.608} & 37 & \multicolumn{2}{|c|}{0.632} & \\
\hline \multirow{4}{*}{ MAP (mm/Hg) } & $(23-32)$ & 27 & 82.28 & 7.72 & 20 & 83.55 & 9.73 & -0.497 \\
\hline & $(33-42)$ & 41 & 83.98 & 8.45 & 13 & 83.10 & 5.62 & 0.351 \\
\hline & $(\geq 43)$ & 32 & 85.13 & 8.20 & 4 & 77.17 & 2.41 & 1.910 \\
\hline & $F$ & 100 & \multicolumn{2}{|c|}{0.888} & 37 & \multicolumn{2}{|c|}{1.077} & \\
\hline
\end{tabular}

Significance at $(<0.05) ;{ }^{* *}(<0.01)$; and ${ }^{* * *}(<0.001)$.

TABLE 3: Correlation $(r)$ of age with SBP, DBP, and MAP among the subjects.

\begin{tabular}{lcc}
\hline Variable & Men $(n=100)$ & Women $(n=37)$ \\
\hline SBP & -0.019 & -0.217 \\
DBP & 0.144 & -0.188 \\
MAP & 0.116 & -0.268 \\
\hline
\end{tabular}

\section{Discussion}

There are at least 970 million people worldwide who have elevated blood pressure (hypertension). In the developed world, about 330 million people have hypertension, as do around 640 million in the developing world. The World Health Organization rates hypertension as one of the most important causes of premature death worldwide and the problem is growing. In 2025 it is estimated that there will be 1.56 billion adults living with high blood pressure [15]. Present study documents a higher prevalence of prehypertension (SBP based) among females (32.4\%) compared to males (25.0\%). The high incidences of hypertension are likely to be important contributors to the epidemic of cardiovascular disease in affluent Indian subjects. The prevalence of hypertension has been increasing in India, both in rural and urban regions [16]. The prevalence of hypertension in urban areas of India ranged from 2.6 to 5.2 percent between 1960 and 1980 (28-30) and it has increased to 20-33 percent in the last decade [17-19]. The prevalence of hypertension was significantly higher in males compared with females, possibly due to the increased prevalence of metabolic risk factors for hypertension and prehypertension in males. Greenland et al. [20] reported that subjects with prehypertension were 1.65 times more likely to have at least 1 other adverse cardiovascular risk factor than those who were normotensive and to have 1.8 times increased

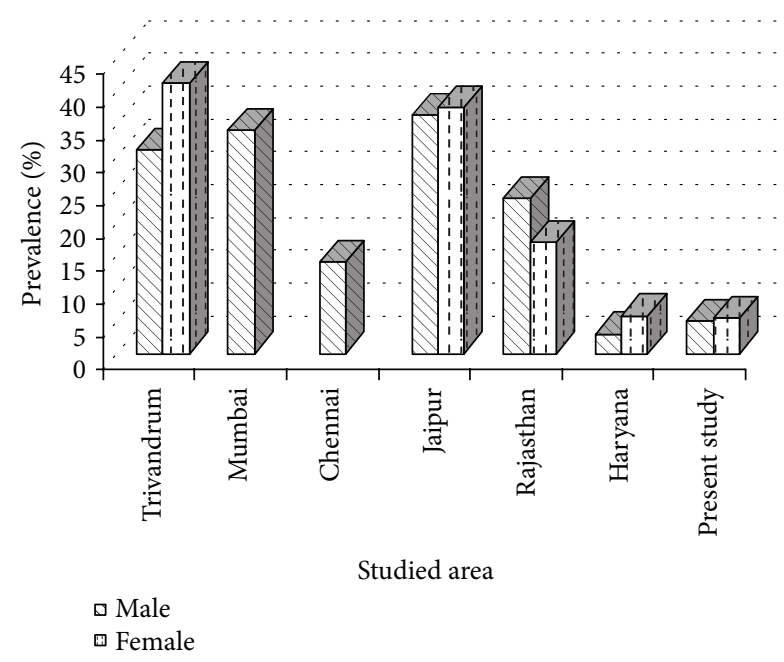

FIGURE 1: Comparative prevalence of hypertension among adults of different parts of India.

risk of cardiovascular events. However, we took concern to select a settlement which had a representative merge of subjects with all different professions and age groups. Figure 1 presents the prevalence of hypertension using SBP and DBP among previously studied adult population in India. Prevalence of hypertension in males was highest in Jaipur (36.4\%) [21] and lowest in Haryana (3.0\%) [22]. Similarly, in females Jaipur adults have highest (37.5\%) [21] and present study females have the lowest (5.4\%).

In addition, the Third National Health and Nutrition Evaluation Survey (NHANES III) showed that, in general, men had higher blood pressure than women through middle age [23]. Furthermore, the incidence of uncontrolled hypertension is also greater in men than in women [24]. Blood 
TABLE 4: Prevalence of prehypertension and hypertension among studied subjects using SBP and DBP.

\begin{tabular}{|c|c|c|c|c|c|c|}
\hline \multirow{2}{*}{ Variable } & \multirow{2}{*}{ Classification } & \multicolumn{2}{|c|}{ Male } & \multicolumn{2}{|c|}{ Female } & \multirow{2}{*}{$\chi^{2}$} \\
\hline & & Frequency & Percent & Frequency & Percent & \\
\hline \multirow{4}{*}{ SBP } & Normal & 70 & 70.0 & 23 & 62.2 & \multirow{4}{*}{0.806} \\
\hline & Prehypertension & 25 & 25.0 & 12 & 32.4 & \\
\hline & Stage I hypertension & 05 & 5.0 & 02 & 5.4 & \\
\hline & Stage II hypertension & 0 & 0 & 0 & 0 & \\
\hline \multirow{4}{*}{ DBP } & Normal & 95 & 95.0 & 35 & 94.6 & \multirow{4}{*}{0.00} \\
\hline & Prehypertension & 0 & 0 & 0 & 0 & \\
\hline & Stage I hypertension & 05 & 5.0 & 02 & 5.4 & \\
\hline & Stage II hypertension & 0 & 0 & 0 & 0 & \\
\hline
\end{tabular}

pressures of 130-9/85-9 in this range are referred to as stage 2 prehypertension [25]. Stage 2 prehypertensives are at about threefold greater risk for progression to hypertension than normal BP persons and approximately double the risk of clinical cardiovascular disease independent of progression to hypertension [25]. Stage 1 prehypertension, that is, 120$129 / 80-84 \mathrm{mmHg}$, is also associated with excess risk but about half that of stage 2 prehypertension when both are compared with normotensives with blood pressure of less than $120 / 80 \mathrm{~mm} \mathrm{Hg}$. [25].

The high prevalence of prehypertension found, especially in women, is a cause of major concern. Given that individuals with prehypertension (especially those at $130-9 / 85-9 \mathrm{mmHg}$ ) are more likely to develop hypertension than normotensive individuals [25], the significant proportion of relatively young subjects (especially women) with prehypertension could lead to an epidemic of hypertension in the next few years. Thus, proactive measures are required to prevent this epidemic.

\section{Conclusion}

The present study is limited by its small sample size, being from monoethnic group of Andhra Pradesh, India. These results may therefore only be representative of a small sample size and not representative of the district, state, or country. To obtain a broader representation, we suggest that more studies involving BP among adults from different parts of India should be undertaken.

However, it may be concluded that the present study, although descriptive in nature, reflects the presence of high blood pressure among females that may lead to higher incidences of cardiovascular diseases among them. Similar studies should be undertaken among various tribal populations of India to identify prehypertensives and hypertensives so that preventive measures could be taken in advance. India is a land of vast ethnic heterogeneity having numerous tribal populations. From the biological anthropology viewpoint, it would be interesting to study variation in blood pressure and hypertension between them. Such descriptive study will help to raise the awareness of an individual to check his/her blood pressure levels in order to not reach hypertensive levels.

\section{Conflict of Interests}

The authors declare that there is no conflict of interests regarding the publication of this paper.

\section{Acknowledgments}

The authors acknowledge all the participants for their valuable time and cooperation during data collection. The authors wish to thank the anonymous referees for their critical comments and helpful suggestions on earlier versions of the paper. The authors thank the university authority for providing the instrument for collecting data.

\section{References}

[1] C. Cuspidi, N. de Luca, and M. Lorenza Muiesan, "Echocariography in hypertension: practicalrecommendation from the Italian Society of Hypertension (SHA)," High Blood Pressure \& Cardiovascular Prevention. In press.

[2] A. W. Gardner and E. T. Poehlman, "Predictors of the age-related increase in blood pressure in men and women," Journals of Gerontology A: Biological Sciences and Medical Sciences, vol. 50, no. 1, pp. M1-M6, 1995.

[3] L. M. Gerber and P. M. Stern, "Relationship of body size and body mass to blood pressure: sex-specific and developmental influences," Human Biology, vol. 71, no. 4, pp. 505-528, 1999.

[4] J. Merlo, K. Asplund, J. Lynch, L. Råstam, and A. Dobson, "Population effects on individual systolic blood pressure: a multilevel analysis of the World Health Organization MONICA Project," American Journal of Epidemiology, vol. 159, no. 12, pp. 1168-1179, 2004.

[5] P. M. McKeigue, B. Shah, and M. G. Marmot, "Relation of central obesity and insulin resistance with high diabetes prevalence and cardiovascular risk in South Asians," The Lancet, vol. 337, no. 8738, pp. 382-386, 1991.

[6] E. A. Enas, "Coronary artery disease epidemic in Indians: a cause for alarm and call for action," Journal of the Indian Medical Association, vol. 98, no. 11, pp. 694-702, 2000.

[7] A. Ghosh, K. Bose, and A. B. Das Chaudhuri, "Comparison of anthropometric characteristics between normotensive and hypertensive individuals among a population of Bengalee Hindu elderly men in Calcutta, India," Journal of the Royal 
Society for the Promotion of Health, vol. 120, no. 2, pp. 100-106, 2000.

[8] E. Thurston, Castes and Tribes of Southern India VI: 207-222, Government Press, Madras, India, 1975.

[9] D. M. S. Kumar and S. Narahari, "The Parangi Porojas: a morpho-genetic study," SAP, vol. 9, pp. 1-5, 1987.

[10] S. D. Sachi and J. M. Naidu, "Paroja/Parja/Porja," in People of India, vol. 13, part 2, pp. 1403-1408, East West Press Private Limited, New Delhi, India, 2003.

[11] S. K. Singh, People of India: The Scheduled Tribes, vol. 3, Oxford University Press, Delhi, India, 1994.

[12] B. Badaruddoza and M. Afzal, "Age-specific differences in blood pressure among inbred and non-inbred north Indian children," Journal of Biosciences, vol. 24, no. 2, pp. 177-184, 1999.

[13] "The Seventh Report of the Joint National Committee on Prevention, Detection, Evaluation, and Treatment of High Blood Pressure: the JNC 7 report," The Journal of the American Medical Association, vol. 289, no. 19, pp. 2560-2571, 2003.

[14] L. Pérusse, T. Rice, C. Bouchard, G. P. Vogler, and D. C. Rao, "Cardiovascular risk factors in a French-Canadian population: resolution of genetic and familial environmental effects on blood pressure by using extensive information on environmental correlates," American Journal of Human Genetics, vol. 45, no. 2, pp. 240-251, 1989.

[15] http://www.world-heart-federation.org/cardiovascular-health /cardiovascular-disease-risk-factors/hypertension/.

[16] S. Yadav, R. Boddula, G. Genitta et al., "Prevalence \& risk factors of pre-hypertension \& hypertension in an affluent north Indian population," Indian Journal of Medical Research, vol. 128, no. 6, pp. 712-720, 2008.

[17] R. Gupta, S. Guptha, V. P. Gupta, and H. Prakash, "Prevalence and determinants of hypertension in the urban population of Jaipur in western India," Journal of Hypertension, vol. 13, no. 10, pp. 1193-1200, 1995.

[18] M. P. Anand, "Prevalence of hypertension amongst Mumbai executives," Journal of Association of Physicians of India, vol. 48, no. 12, pp. 1200-1201, 2000.

[19] C. S. Shanthirani, R. Pradeepa, R. Deepa, G. Premalatha, R. Saroja, and V. Mohan, "Prevalence and risk factors of hypertension in a selected South Indian population-the Chennai Urban Population Study," Journal of Association of Physicians of India, vol. 51, pp. 20-27, 2003.

[20] K. J. Greenland, J. B. Croft, and G. A. Mensah, "Prevalence of heart disease and stroke risk factors in persons with prehypertension in the United States, 1999-2000," Archives of Internal Medicine, vol. 164, no. 19, pp. 2113-2118, 2004.

[21] R. Gupta, V. P. Gupta, M. Sarna et al., "Prevalence of coronary heart disease and risk factors in an urban Indian population: Jaipur Heart Watch-2," Indian Heart Journal, vol. 54, no. 1, pp. 59-66, 2002.

[22] P. Malhotra, S. Kumari, R. Kumar, S. Jain, and B. K. Sharma, "Prevalence and determinants of hypertension in an unindustrialised rural population of North India," Journal of Human Hypertension, vol. 13, no. 7, pp. 467-472, 1999.

[23] V. L. Burt, P. Whelton, E. J. Roccella et al., "Prevalence of hypertension in the US adult population: results from the third National Health and Nutrition Examination Survey, 1988-1991," Hypertension, vol. 25, no. 3, pp. 305-313, 1995.

[24] K. Anastos, P. Charney, R. A. Charon et al., "Hypertension in women: what is really known? The Women's Caucus, Working Group on Women's Health of the Society of General Internal
Medicine," Annals of Internal Medicine, vol. 115, no. 4, pp. 287293, 1991

[25] B. M. Egan and S. Julius, "Prehypertension: risk stratification and management considerations," Current Hypertension Reports, vol. 10, no. 5, pp. 359-366, 2008. 

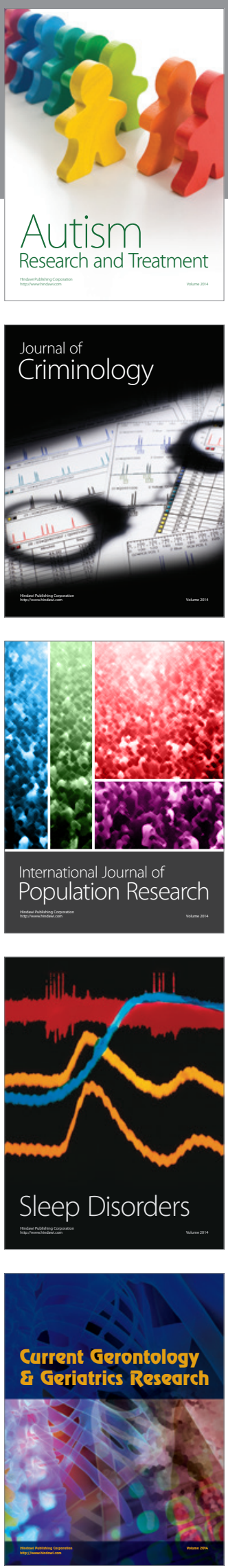
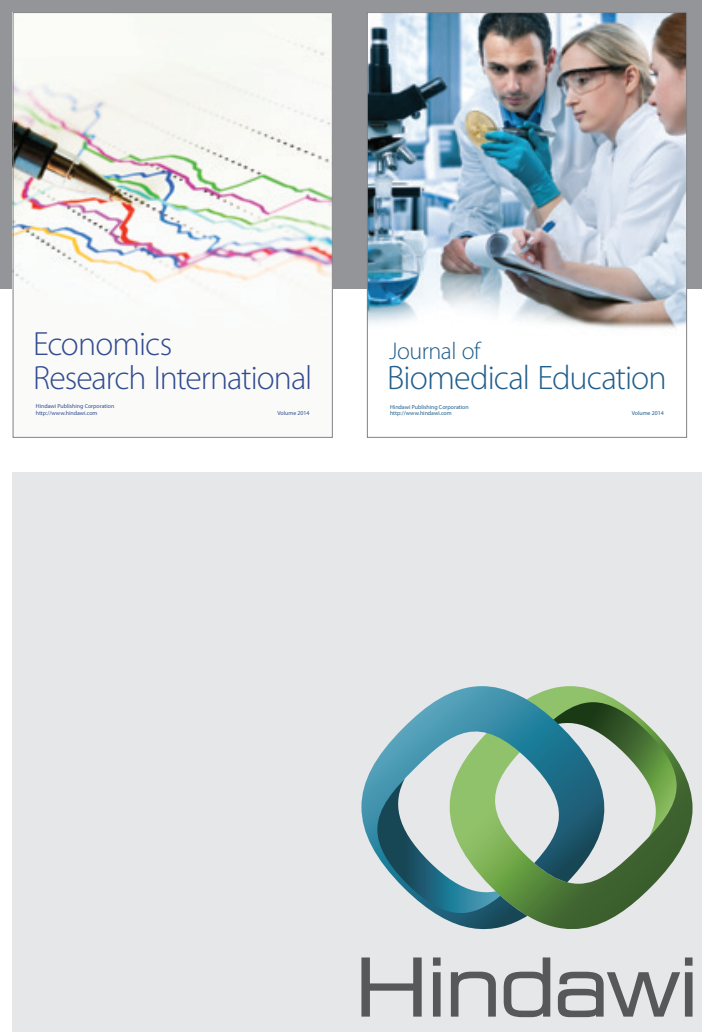

Submit your manuscripts at

http://www.hindawi.com
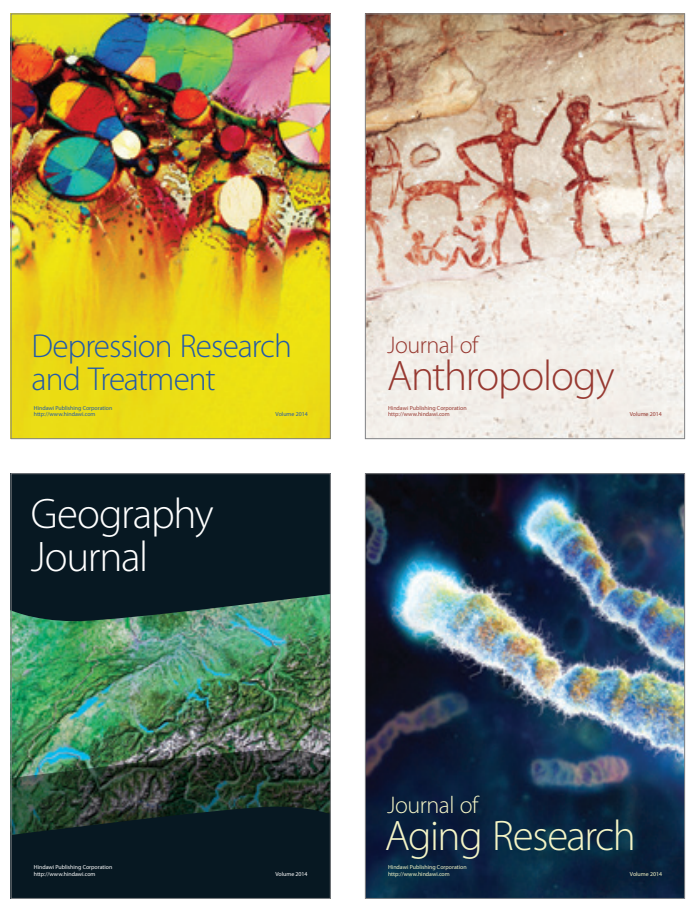
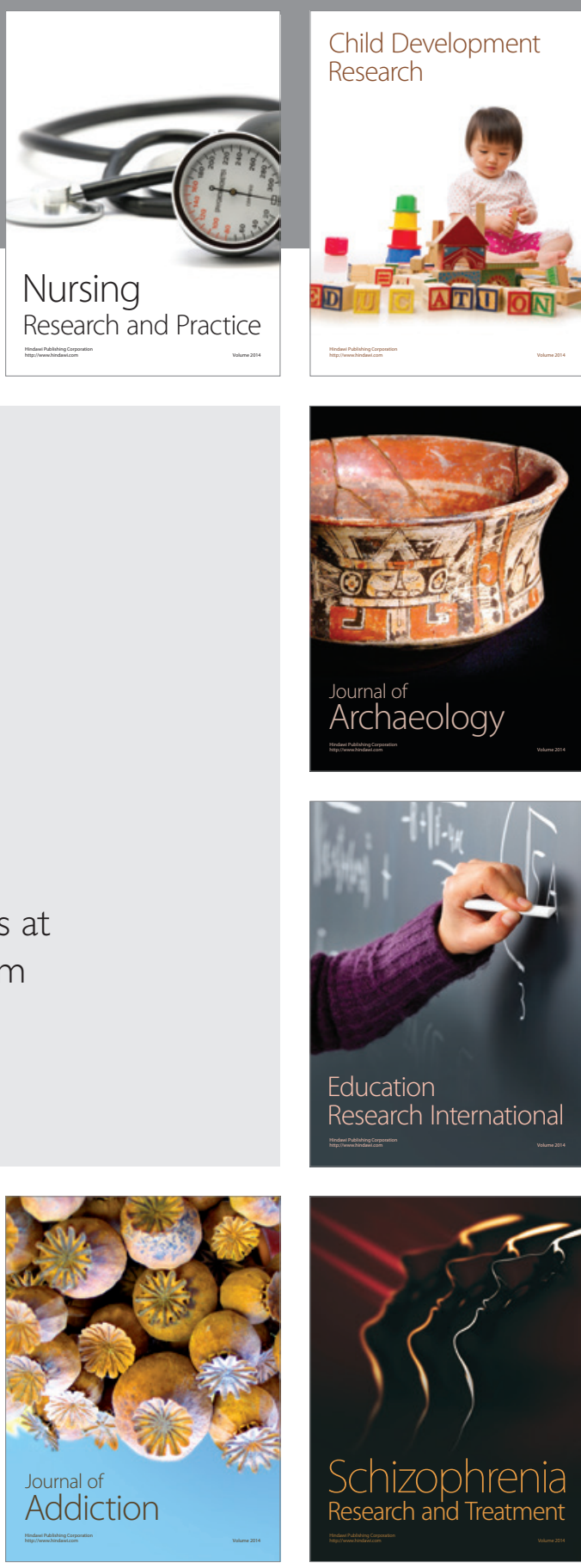

(D)
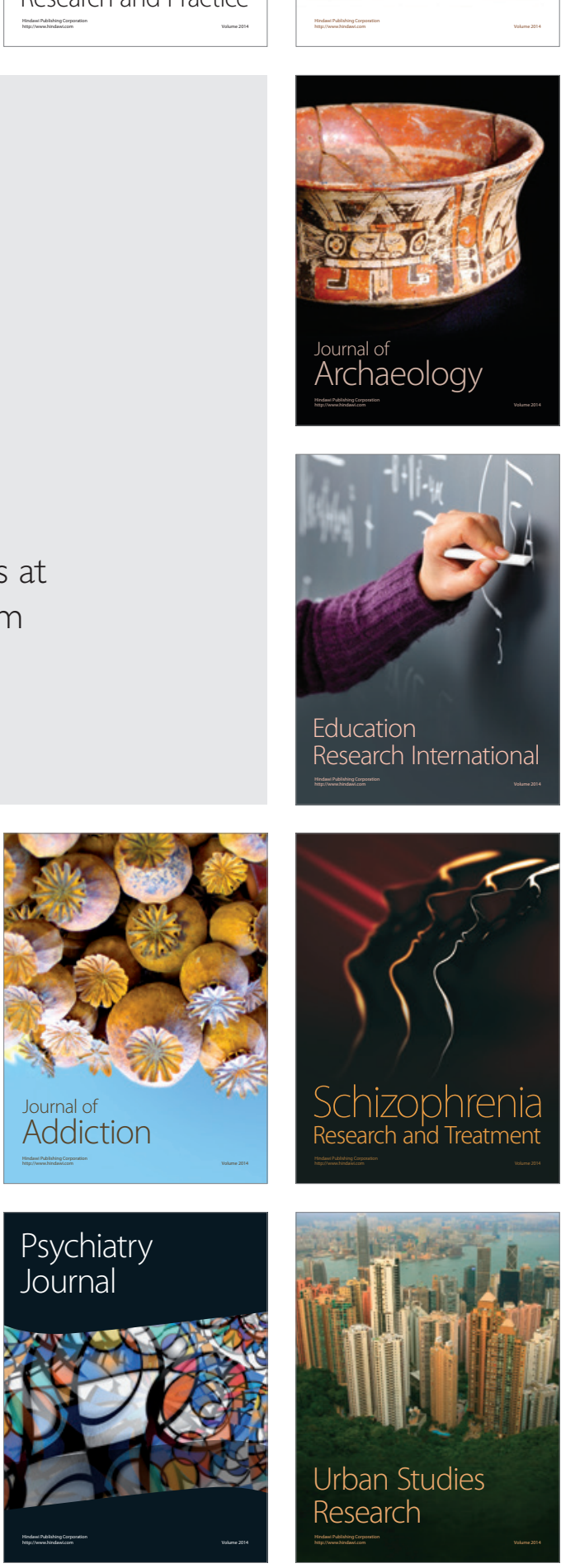